\title{
Sound production as an indicator of red hind density at a spawning aggregation
}

\author{
Timothy J. Rowell ${ }^{1, *}$, Michelle T. Schärer ${ }^{1}$, Richard S. Appeldoorn ${ }^{1}$, \\ Michael I. Nemeth ${ }^{1}$, David A. Mann ${ }^{2}$, José A. Rivera ${ }^{3}$ \\ ${ }^{1}$ Department of Marine Sciences, University of Puerto Rico, Mayagüez, Puerto Rico 00681-9013, USA \\ ${ }^{2}$ College of Marine Science, University of South Florida, St. Petersburg, Florida 33701, USA \\ ${ }^{3}$ NOAA National Marine Fisheries, Habitat Conservation Division, Southeast Regional Office, St. Petersburg, Florida 33701, USA
}

\begin{abstract}
Annual spawning aggregations of red hind Epinephelus guttatus form at predictable times and locations and have historically succumbed to overfishing. Monitoring the status and restoration of aggregations is essential for evaluating the effectiveness of fishery management measures. Passive acoustic and diver-based underwater visual census (UVC) techniques were used to develop an efficient method for estimating red hind density from sound production at spawning aggregations. Red hind sound production was recorded from November 2010 to April 2011 at Abrir la Sierra, Puerto Rico. UVC surveys were conducted during the spawning season to assess changes in red hind density over a fixed time and area. Sound recorded from 18:00 to 19:00 $\mathrm{h}$ Atlantic Standard Time (UTC - 4) was representative of total daily changes in red hind sound production and was selected for the development of an efficient density estimation model. Pronounced daily changes in sound production and density were observed after the December 2010 and January 2011 full moons. Two hourly sound level measurements were compared to densities estimated by UVC surveys, yielding significant linear regressions, which were used to predict changes in fish density as measured at the aggregation site. Passive acoustic methods allowed to predict changes in red hind density and habitat use at a higher temporal resolution than previously possible with traditional methods. Red hind sound production and inferred densities can be monitored and analyzed efficiently for multiple aggregation sites simultaneously, documenting short-term and long-term changes in red hind densities at spawning aggregation sites and providing important information for the support or development of management strategies.
\end{abstract}

KEY WORDS: Epinephelus guttatus - Passive acoustics - Reproduction - Behavior - Fishery management $\cdot$ Puerto Rico $\cdot$ Abrir la Sierra $\cdot$ Marine protected areas

\section{INTRODUCTION}

Red hind Epinephelus guttatus is a commercially and recreationally important protogynous grouper (Epinephelidae) found from Bermuda to Brazil that reproduces during annual transient spawning aggregations at specific times and locations (Colin et al. 1987, Shapiro et al. 1993a, 1994, Sadovy et al. 1994, Cummings et al. 1996, Domeier \& Colin 1997,
Nemeth 2012). On the Puerto Rico (PR) and United States Virgin Islands (USVI) shelf platform, aggregation formation and spawning occur during the week around the full moons in either December and January, January and February, or only January (Colin et al. 1987, Shapiro et al. 1993b, Sadovy et al. 1994, Whiteman et al. 2005), depending on when the full moon occurs each month in relation to the winter solstice (Nemeth et al. 2007). Aggregation formation 
typically begins with the arrival of males prior to the first full moon of the spawning season, followed by the appearance of females (Whiteman et al. 2005, Nemeth et al. 2008). Red hind densities in aggregations vary over the course of the spawning period, characterized by a build up prior to each spawning event followed by a quick departure from the site after spawning, with 5 to $20 \%$ of individuals remaining on location between consecutive full moons (Nemeth et al. 2007).

The predictability of grouper aggregations makes them extremely vulnerable to overfishing, which can result in a decrease in stock size, mean length, and recruitment, diminished density and biomass, female biased sex ratios, or complete disappearance of the aggregation (Beets \& Friedlander 1992, Sadovy \& Figuerola 1992, Sadovy 1994, Aguilar-Perera \& Aguilar-Dávila 1996, Coleman et al. 1996, Sadovy \& Domeier 2005, Aguilar-Perera 2006). In the USVI, protecting red hind spawning aggregations through seasonal and subsequently permanent no-take marine protected areas (MPAs) has reversed these trends and led to a substantial stock recovery (Beets \& Friedlander 1999, Nemeth 2005). Similarly, in Bermuda, seasonal protections at red hind spawning aggregation sites have likely resulted in increases in mean and modal sizes (Luckhurst \& Trott 2008). In contrast, seasonal closures in PR have not shown positive results due to considerable increases in effort both outside the closed areas and outside the closed season (Marshak \& Appeldoorn 2007) coupled with a lack of compliance by fishermen and vendors as well as minimal enforcement of regulations during the closed season (García-Sais et al. 2008, authors' pers. obs.). However, if the compatible seasonal restrictions throughout PR and federal jurisdiction waters are adhered to and enforcement efforts increase, spawning stocks of red hind may start to recover (Marshak \& Appeldoorn 2007).

Monitoring the effectiveness of fishery management measures is essential for determining the shortterm and long-term benefits of different strategies. Traditional methods of monitoring and studying red hind aggregations include hook and line, trap fishing, spear fishing, fishermen surveys, gonad analyses, tagging studies, and diver surveys (Colin et al. 1987, Shapiro et al. 1993a, 1994, Sadovy et al. 1994, Nemeth 2005, Whiteman et al. 2005, Nemeth et al. 2007, Cushion et al. 2008). These methods are often time consuming, expensive, and potentially destructive. In addition, many red hind spawning aggregations are located along insular shelf break areas (Shapiro et al. 1993a, Sadovy et al. 1994, Nemeth
2005), where conditions are often adverse, making data collection difficult and limited.

Passive acoustics is a novel and efficient tool that can be used to study and monitor soniferous fish behavior and habitat use and to collect long-term datasets that would be difficult to acquire with traditional methods (Myrberg 1997, Luczkovich \& Sprague 2002, Rountree et al. 2006, Luczkovich et al. 2008a, Mann et al. 2008). Sound production in a number of species is known to be associated with courtship, territoriality, or reproduction, warranting the use of passive acoustics to locate spawning aggregations (Luczkovich et al. 1999, 2008b, Walters et al. 2009, Rowell et al. 2011) and determine temporal spawning behavior and habitat use by different species (Locascio \& Mann 2008, Mann et al. 2009, 2010, Nelson et al. 2011, Schärer et al. 2012).

Red hind produce a low frequency mixed tonalpulse species-specific vocalization associated with courtship and territorial behaviors at spawning aggregations (Mann \& Locascio 2008, Mann et al. 2010). Daily sound levels show trends similar to the density build-up and post-spawning departure described by Nemeth et al. (2007), with maximum levels around sunset (Mann et al. 2010) when red hind have been observed spawning (Colin et al. 1987). While passive acoustic methods have been used to describe patterns of sound production at red hind spawning aggregations, the relationship between changes in red hind sound production and density has not been established.

The purposes of this study were to examine if changes in densities are reflected by changes in sound production in a quantitative manner, determine if density can be predicted from sound measurements recorded passively, and develop an efficient passive acoustic methodology to monitor red hind densities, spawning activity, and efficacy of fishery protections at spawning aggregations.

\section{MATERIALS AND METHODS}

\section{Study site}

Audio recordings and diver-based underwater visual census (UVC) surveys were conducted at Abrir la Sierra (ALS), a known and previously studied red hind spawning aggregation site off the west coast of Cabo Rojo, PR (Fig. 1). The aggregation site is situated at a depth of 20 to $30 \mathrm{~m}$. The substratum is a low rugosity hard bottom that is sparsely colonized by sponges, gorgonians, and scleractinians. As of 1996, 


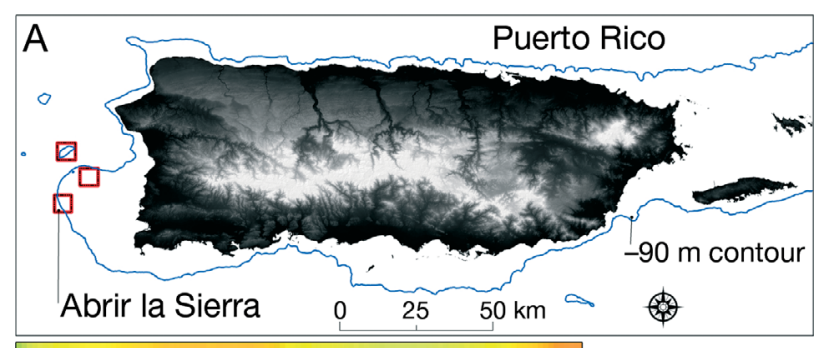

B

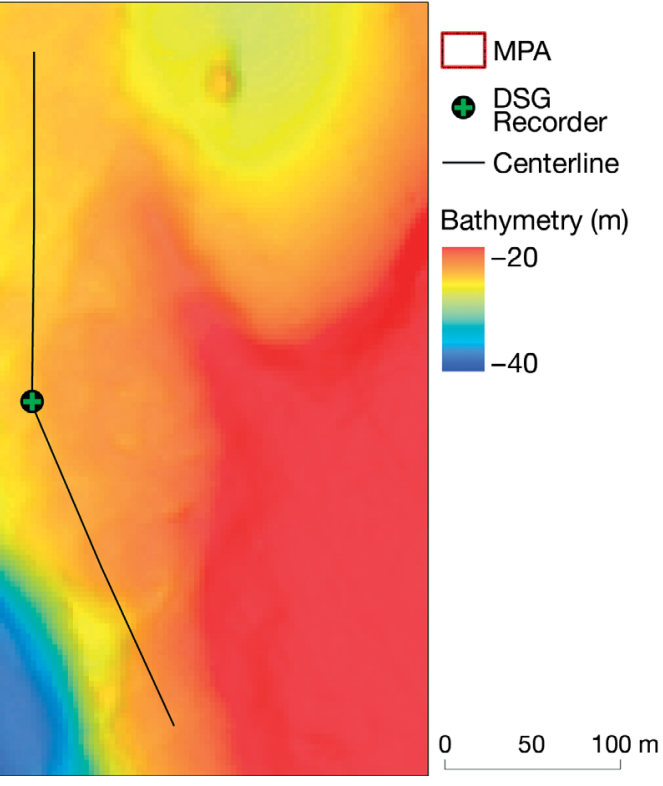

Fig. 1. (A) Location and (B) bathymetric map of the study site Abrir la Sierra with underwater visual census survey centerline and digital spectrogram (DSG) long-term audio recorder location indicated by center point. The seasonal marine protected areas (MPAs) of Abrir la Sierra, Tourmaline, and Bajo de Sico are outlined in red in (A)

in conjuncture with 2 other sites (Tourmaline and Bajo de Sico), ALS has been closed to all fishing from
1 December to the last day of February to protect the red hind spawning aggregation (CFMC 1996). In 2004, a fishing ban on red hind during the spawning period was established for all PR waters $(<9$ nautical miles offshore) (PR DRNA 2004), which in 2005 was expanded to include all PR and federal waters west of $67^{\circ} 10^{\prime} \mathrm{W}$ (Federal Register 2005, PR DRNA 2007).

\section{Acoustic recordings}

A digital spectrogram long-term acoustic recorder (DSG; Loggerhead Instruments) was deployed at ALS from 17 November 2010 until 30 April 2011 to passively record acoustic signals. This unit consisted of a cylindrical PVC housing, single hydrophone (sensitivity $=-186 \mathrm{dBV} \mu \mathrm{Pa}^{-1}$; frequency range 2 to $37 \mathrm{kHz}$ ), micro-computer, circuit board, and 24 D-cell alkaline batteries. The DSG board incorporated an additional $20 \mathrm{~dB}$ gain and was calibrated with a $0.1 \mathrm{~V}_{\text {peak }}$ frequency sweep from $2 \mathrm{~Hz}$ to $100 \mathrm{kHz}$. Files were digitized at a sample rate of $15094 \mathrm{~Hz}$ for 20 s every 5 min onto a 16 GB removable secure digital high capacity (SDHC) flash memory card. The DSG recorder was attached with hose clamps to rebar located within the aggregation site as estimated by previous UVC and acoustic surveys.

\section{Underwater visual census surveys}

A GPS-density survey method (P. Colin pers. comm.) was used for the UVC on $12 \mathrm{~d}$ from November 2010 to February 2011 (Table 1). Prior to the spawning season, a $400 \mathrm{~m}$ long by $100 \mathrm{~m}$ wide area

Table 1. Epinephelus guttatus. Mean densities $\mathrm{d}^{-1}$ (ind. $100 \mathrm{~m}^{-2}$ ), standardized total vocalizations $\mathrm{h}^{-1}$, and mean band levels $\mathrm{h}^{-1}(100-200 \mathrm{~Hz}$; dB re $1 \mu \mathrm{Pa}$ ) from 18:00 to 19:00 h AST on days in which underwater visual census surveys were conducted. Sound measurements on days with truncated and excluded acoustic data are indicated as not available (na)

\begin{tabular}{|c|c|c|c|c|c|}
\hline Date & $\begin{array}{l}\text { Days after } \\
\text { full moon }\end{array}$ & $\begin{array}{c}\text { Days after } \\
\text { winter solstice }\end{array}$ & $\begin{array}{c}\text { Mean } \\
\text { density } \pm \text { SD }\end{array}$ & Vocalizations & $\begin{array}{l}\text { Mean band } \\
\text { level } \pm \text { SD }\end{array}$ \\
\hline 17 Nov 2010 & 25 & - & $0.17 \pm 0.02$ & 0 & $99.2 \pm 0.8$ \\
\hline 20 Dec 2010 & 29 & - & $0.16 \pm 0.05$ & 0 & $99.8 \pm 0.8$ \\
\hline 27 Dec 2010 & 6 & 6 & $1.04 \pm 0.28$ & 135 & $102.6 \pm 1.4$ \\
\hline 14 Jan 2011 & 24 & 24 & $0.81 \pm 0.48$ & na & na \\
\hline 19 Jan 2011 & 0 & 29 & $0.51 \pm 0.07$ & 300 & $104.9 \pm 1.0$ \\
\hline 23 Jan 2011 & 4 & 33 & $1.37 \pm 0.23$ & na & na \\
\hline 25 Jan 2011 & 6 & 35 & $2.11 \pm 0.68$ & 450 & $108.0 \pm 1.6$ \\
\hline 27 Jan 2011 & 8 & 37 & $3.15 \pm 0.16$ & 420 & $108.7 \pm 1.4$ \\
\hline 29 Jan 2011 & 10 & 39 & $1.68 \pm 0.17$ & 285 & $107.6 \pm 2.4$ \\
\hline 05 Feb 2011 & 17 & 46 & 0.08 & 0 & $100.4 \pm 1.1$ \\
\hline 20 Feb 2011 & 2 & 61 & 0.20 & 0 & $99.9 \pm 0.9$ \\
\hline 23 Feb 2011 & 5 & 64 & $0.10 \pm 0.05$ & 0 & $100.9 \pm 0.8$ \\
\hline
\end{tabular}


was established, with the centerline marked by subsurface buoys. The DSG was located in the middle of the $400 \mathrm{~m}$ length of the area along the centerline (Fig. 1). GPS-UVC surveys were conducted on each side of the centerline to assess red hind density over a fixed area. Surveys were conducted from north to south or the reverse direction depending on the current's direction at each sampling. Red hind distributions at aggregation sites are relatively fixed, with males protecting a given territory and harem (Shapiro et al. 1993a); therefore, surveying the area repeatedly allowed for the documentation of daily changes in density while minimizing variance due to clustering effects.

UVC surveys began at 16:00 h Atlantic Standard Time (AST; UTC - 4) when light levels were favorable and red hind territorial, reproductive, and acoustic behaviors were known to be increasing from midday levels (Mann et al. 2010, T. J. Rowell pers. obs.); sunset occurred between 17:46 and 18:46 h AST during the study period. Two parallel belt transect surveys measuring $4 \mathrm{~m}$ wide were conducted simultaneously within the survey area on all days except 5 February and 20 February, when a single survey was made. Each diver towed a handheld GPS unit (Garmin GPSMAP 76Cx) attached to a surface buoy as a $30 \mathrm{~s}$ interval geographic coordinate track was recorded. With the survey start and end time, the length of each transect was calculated and multiplied by $4 \mathrm{~m}$ to determine the total area surveyed by each diver. During the survey, the number, size (total length in $\mathrm{cm}$ ), and condition (behavior, coloration, and gravid state) of each red hind was noted as well as the time of the observation. Red hind density (number of fish $100 \mathrm{~m}^{-2}$ ) was calculated for each survey by dividing the total the number of red hind by the total area surveyed. Mean fish density $\mathrm{d}^{-1}(D)$ and standard deviation was calculated from the 2 transects when available.

\section{Analysis of acoustic recordings}

Audio files were extracted from the SDHC cards and converted into WAV files. Red hind vocalizations from all recordings each day (00:00 to 23:55 h AST) were visually and audibly identified in Ishmael 2.0 (CIMRS Bioacoustics Lab) from spectrograms generated with a Hamming window and frame size of 2048 samples. Vocalizations were summed for each day and multiplied by 15 to account for the $20 \mathrm{~s}$ every 5 min sampling schedule, yielding an estimate of total vocalizations $\mathrm{d}^{-1}$. Following Mann et al. (2010), received sound pressure levels in the 100 to $200 \mathrm{~Hz}$ frequency band (band levels) were used as a second measurement of red hind sound production; the majority of red hind acoustic energy is within the 100 to $200 \mathrm{~Hz}$ band. Band levels were calculated in a custom MATLAB (The Mathworks) software called DSGLab. DSGLab calculates the band level (dB relative to [re] $1 \mu \mathrm{Pa}$ ) in the 100 to $200 \mathrm{~Hz}$ frequency band using 6-pole Butterworth (i.e. $36 \mathrm{~dB}$ octave $^{-1}$ ) high and low pass filters, a root-mean-square calculation, and a hydrophone calibration adjustment. The resulting band levels incorporated all received sound within the 100 to $200 \mathrm{~Hz}$ band into 1 value for each $20 \mathrm{~s}$ file. Band levels were averaged for each day to generate a mean band level $\mathrm{d}^{-1}$.

To determine if a single hour could be used to document daily changes in red hind sound production, in lieu of inspecting all $24 \mathrm{~h}$ and thereby increasing data processing efficiency in the future, total vocalizations $\mathrm{h}^{-1}$ and mean band levels $\mathrm{h}^{-1}$ were calculated for 18:00 to 19:00 h AST and compared to the 00:00 to 23:55 h AST values. The 18:00 to 19:00 h AST period was chosen as it was the closest hour period to the diver surveys without research vessel noise interference and coincided with the known time of red hind spawning (Colin et al. 1987) and daily peak sound production (Mann et al. 2010, T. J. Rowell obs. comm.). Regression statistics of total vocalizations $\mathrm{d}^{-1}$ (00:00 to $23: 55 \mathrm{~h}$ AST) vs. total vocalizations $\mathrm{h}^{-1}$ (18:00 to 19:00 $\mathrm{h}$ AST) and mean band level $\mathrm{d}^{-1}(00: 00$ to $23: 55 \mathrm{~h}$ AST) vs. mean band level $\mathrm{h}^{-1}$ (18:00 to 19:00 h AST) were calculated using Excel data analysis tools (Microsoft).

Daily recordings from 18:00 to 19:00 h AST were re-examined to quantify vocalizations and develop a standardized replicable methodology that limits analyst variability regarding which vocalizations should be included in the analyses, i.e. how loud a vocalization needs to be. Vocalizations were manually identified and isolated for each $20 \mathrm{~s}$ file in Adobe Audition 3 (Adobe Systems) from spectrograms generated with a Hamming window and resolution of 1024 points. The isolated red hind vocalizations were then verified audibly. Band levels (100 to $200 \mathrm{~Hz}$ ) for each isolated vocalization were calculated in MATLAB as previously described. Individual vocalizations with a band level of $\geq 105 \mathrm{~dB}$ re $1 \mu \mathrm{Pa}$ were quantified for each file. For each day, vocalizations were summed and multiplied by 15, correcting for the sampling schedule, to estimate standardized total vocalizations $\mathrm{h}^{-1}$ (18:00 to 19:00 h AST).

Regression equations were generated (Excel) for mean $D$ vs. standardized total vocalizations $\mathrm{h}^{-1}(18: 00$ 
to $19: 00 \mathrm{~h} \mathrm{AST}$ ) and mean $D$ vs. mean band level $\mathrm{h}^{-1}$ (18:00 to 19:00 h AST) on days in which both survey density and passive acoustic data were collected. A regression between standardized total vocalizations $\mathrm{h}^{-1}$ (18:00 to $19: 00 \mathrm{~h}$ AST) and mean band level $\mathrm{h}^{-1}$ (18:00 to 19:00 $\mathrm{h}$ AST) was also examined for the entire recorded period. Fish density was predicted for the entire sampling period from the standardized total vocalizations $\mathrm{h}^{-1}$ and mean band level $\mathrm{h}^{-1}$ vs. mean $D$ regression equations.

\section{RESULTS}

UVC surveys were successfully conducted throughout the preset area on all days except 19 January, when divers were diverted from the centerline of the survey area by strong currents. Survey data demonstrated 2 periods of increased red hind density (Table 1, Fig. 2). Density increased following the full moons on 21 December 2010 and 19 January 2011 and abruptly decreased in the beginning of February.

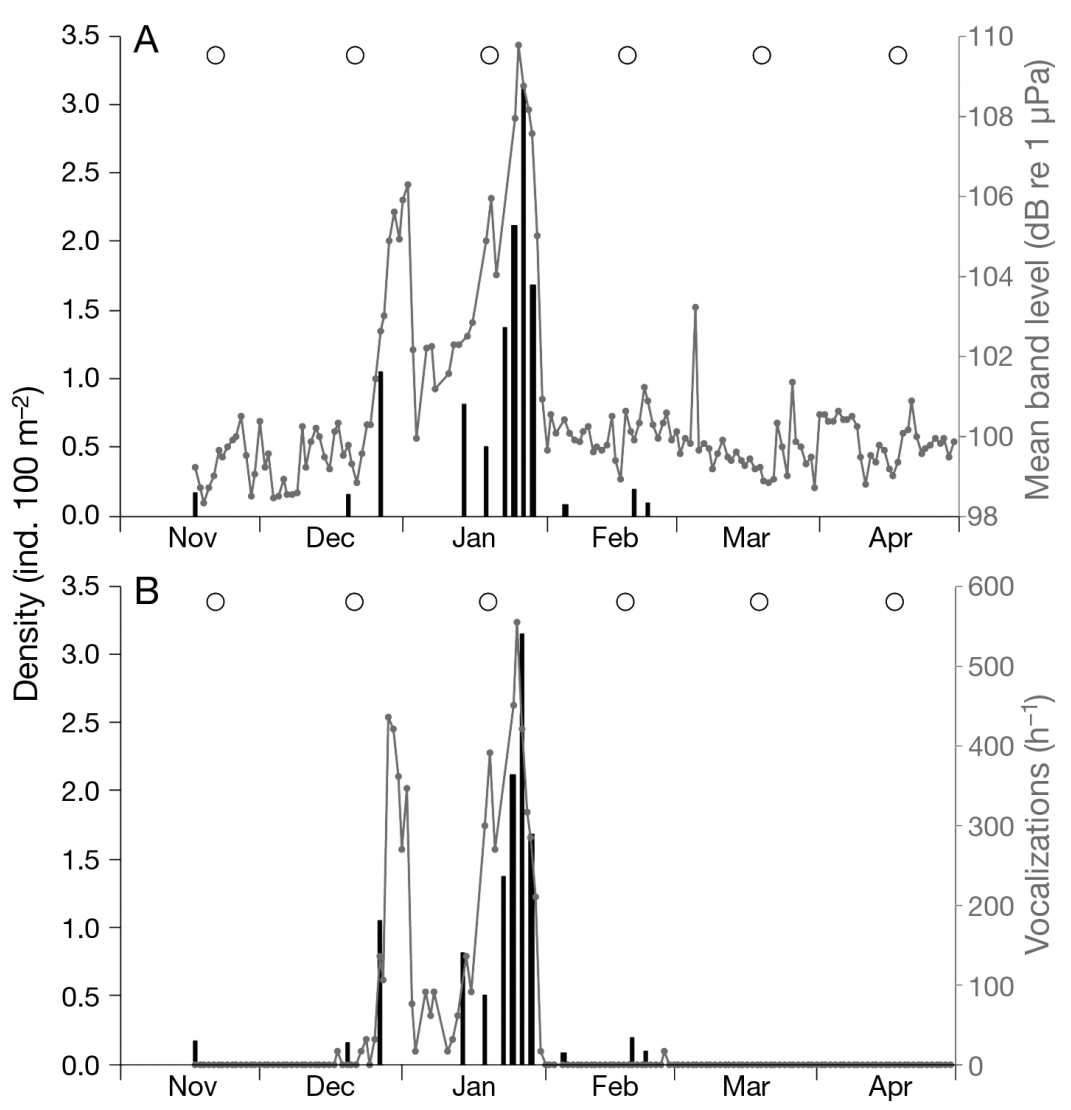

Fig. 2. Epinephelus guttatus. Surveyed densities (black bars; underwater visual census, $\mathrm{n}=12$ ) with (A) mean band levels $\mathrm{h}^{-1}(100-200 \mathrm{~Hz}$; $\mathrm{dB}$ re $1 \mu \mathrm{Pa}$; line) and (B) standardized total vocalizations $\mathrm{h}^{-1}$ (line) from 18:00 to 19:00 $\mathrm{h}$ AST for the entire sampling period. O: full moon
Diver surveys were only conducted twice in December (vs. 6 times in January), limiting conclusions of when density likely peaked in December. During the days surveyed in January, density peaked on 27 January, $8 \mathrm{~d}$ after the full moon (DAFM). Fish density in between the full moons of December and January was above the non-spawning season resident density but markedly lower than peak density in January.

The DSG audio recorder successfully recorded sound at the aggregation site from 18:00 to 19:00 h AST on all days during the sampling period, with the exception of $10 \mathrm{~d}$. On 5, 9-10, 14, 17, 18, and 22-24 January and 4 February there was a malfunction with the SDHC flash memory card that resulted in the truncation of select files during the extraction process. These $10 \mathrm{~d}$ were excluded from all analyses of sound production. Linear regressions were significant for total vocalizations $\mathrm{d}^{-1}$ (00:00 to 23:55 h AST) vs. total vocalizations $\mathrm{h}^{-1}$ (18:00 to 19:00 $\mathrm{h} \mathrm{AST} ; \mathrm{r}^{2}=0.724, \mathrm{p}<$ $0.001)$ and mean band level $d^{-1}$ (00:00 to 23:55 h AST) vs. mean band level $\mathrm{h}^{-1}$ (18:00 to 19:00 $\mathrm{h} \mathrm{AST}$; $\mathrm{r}^{2}=$ 0.674, $\mathrm{p}<0.001$ ). Therefore, the 18:00 to 19:00 h AST time period was selected as a suitable indicator of daily changes in red hind sound production for the development of an efficient replicable procedure to relate sound production to density.

Mean band levels $\mathrm{h}^{-1}$ (18:00 to 19:00 h AST) and standardized total vocalizations $h^{-1}$ (18:00 to 19:00 $h$ AST) reveal 2 periods of increased sound production following the December and January full moons (Fig. 2). Mean band levels and total vocalizations began to prominently increase 4 and 5 DAFM in December, respectively. Mean band levels peaked 11 DAFM (1 January) and vocalizations peaked 8 DAFM (29 December) before both rapidly fell 13 DAFM. During the interim period between the December and January full moons, sound production was relatively low compared to the highest red hind generated levels measured but was still above non-spawning period levels. Both sound measurements began to again increase steeply on 19 January, the day of the full moon, before reaching their maxima 7 DAFM. Sound production began to fall markedly 11 DAFM in January, 
returning to non-spawning period sound levels 13 DAFM. The duration of elevated sound production was broader in January than December, with band levels and vocalization frequencies also higher following the January full moon. There was no increased sound production associated with the February full moon.

Linear regressions were significant for mean band level $\mathrm{h}^{-1}$ (18:00 to 19:00 h AST) vs. mean $D\left(\mathrm{r}^{2}=0.83\right.$, $\mathrm{p}<0.001$ ) (Fig. 3A), standardized total vocalizations $\mathrm{h}^{-1}\left(18: 00\right.$ to $19: 00 \mathrm{~h}$ AST) vs. mean $D\left(\mathrm{r}^{2}=0.778, \mathrm{p}<\right.$ 0.001) (Fig. 3B), and mean band level $h^{-1}$ (18:00 to 19:00 h AST) vs. standardized total vocalizations $\mathrm{h}^{-1}$ (18:00 to 19:00 h AST; $\left.\mathrm{r}^{2}=0.831, \mathrm{p}<0.001\right)$. The linear regressions of mean band level $\mathrm{h}^{-1}(L)$ and vocalizations $\mathrm{h}^{-1}(V)$ with mean $D$ yielded 2 equations (Eqs. 1, 2), respectively, which were used to predict red hind density:

$$
\begin{aligned}
& D=0.2583(L)-25.736 \\
& D=0.005(V)+0.1203
\end{aligned}
$$

Density predicted from both mean band level $\mathrm{h}^{-1}$ and standardized total vocalizations $\mathrm{h}^{-1}$ depicts density patterns over the entire sampling period at ALS (Fig. 4).

\section{DISCUSSION}

The significant regressions of sound production from 18:00 to 19:00 h AST vs. sound production from 00:00 to 23:55 $\mathrm{h}$ AST revealed that the 18:00 to 19:00 h AST period reflected patterns of daily changes in vocalization totals and mean band levels. As a result, selecting the 18:00 19:00 h AST period for comparison to density accurately depicted daily changes in sound production without requiring the examination of all $24 \mathrm{~h}$. The selection of the 18:00 to 19:00 $\mathrm{h}$ AST period was based on a thorough understanding of red hind acoustic and reproductive behavior coupled with the dependent timing of diver surveys: red hind sound production has a diel periodicity, peaking around dusk (Mann et al. 2010) and with lulls at midday and midnight (T. J. Rowell pers. obs.). This contrasts, for example, aggregating goliath grouper, Epinephelus itajara, whose sound production peaks be-

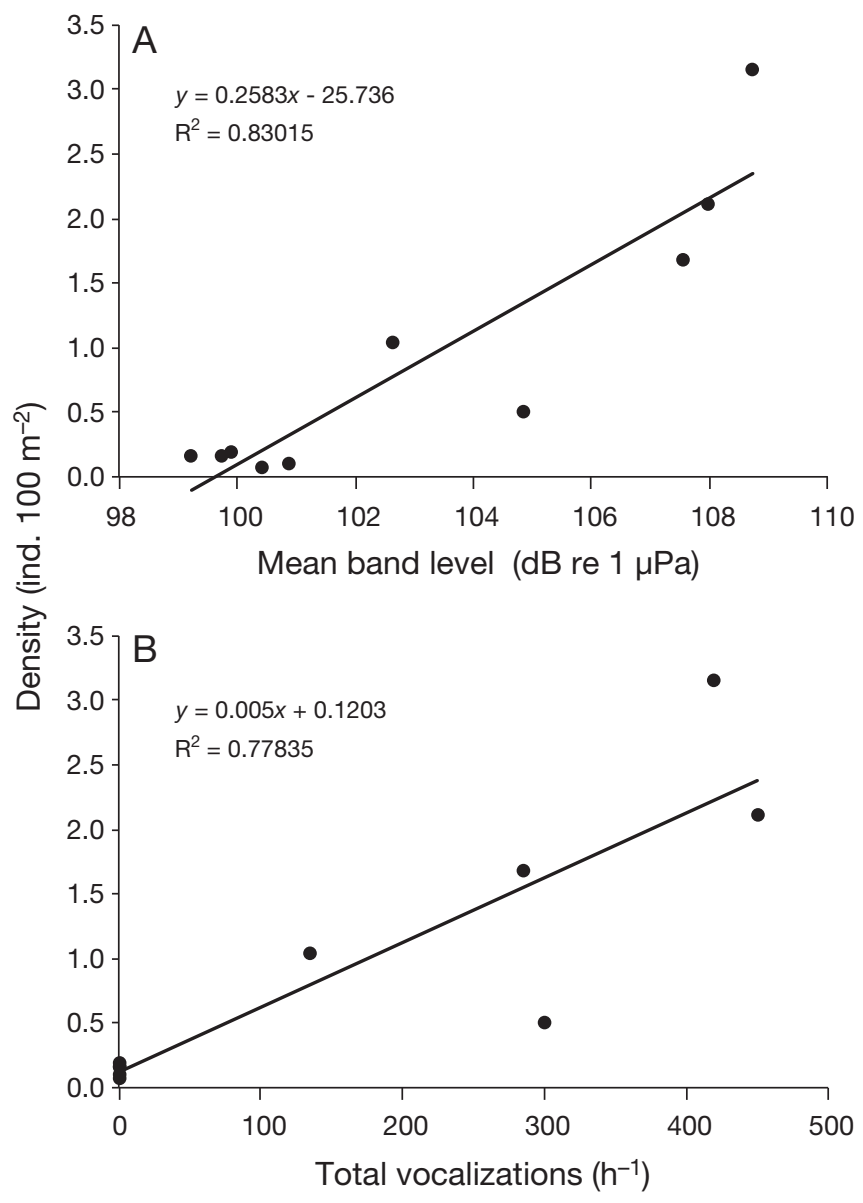

Fig. 3. Epinephelus guttatus. Regressions of surveyed density vs. (A) mean band level $\mathrm{h}^{-1}(\mathrm{p}<0.001)$ and (B) standardized total vocalizations $\mathrm{h}^{-1}(\mathrm{p}<0.001)$ from 18:00 to 19:00 $\mathrm{h}$ AST on days in which both underwater visual census density and passive acoustic data were collected

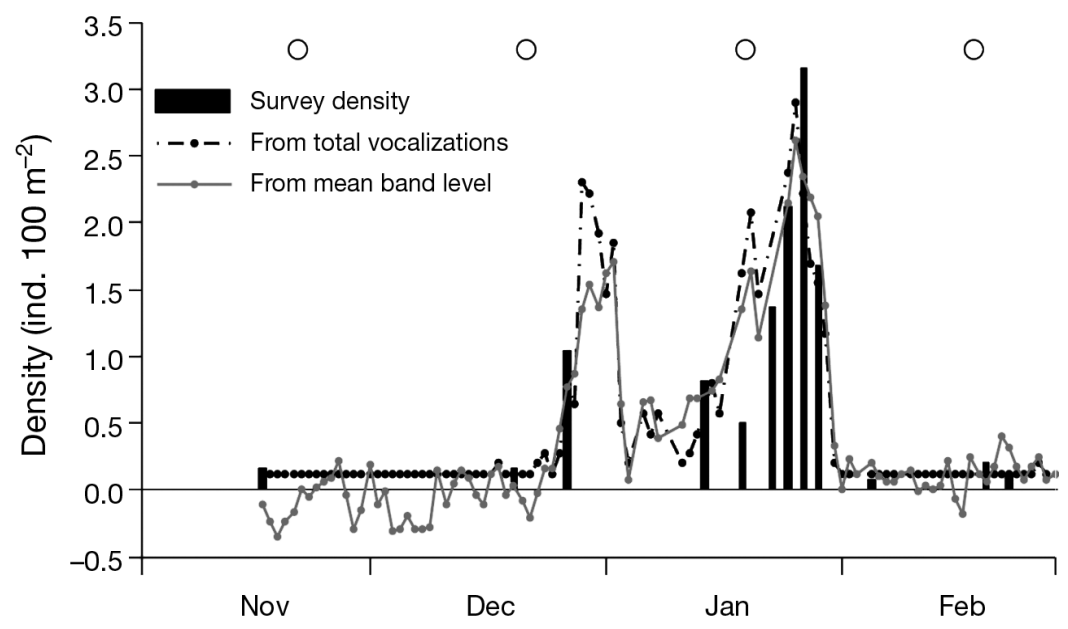

Fig. 4. Epinephelus guttatus. Densities (ind. $100 \mathrm{~m}^{-2}$ ) from underwater visual census surveys (black bars, $\mathrm{n}=12$ ), and predicted densities from standardized total vocalizations $\mathrm{h}^{-1}$ (dashed black line) and mean band levels $\mathrm{h}^{-1}(100-$ $200 \mathrm{~Hz}$; dB re $1 \mu \mathrm{Pa}$; solid grey line). O: full moon 
tween 01:00 to $04: 00 \mathrm{~h}$ and from 18:00 to $19: 00 \mathrm{~h}$ is relatively quiet (Mann et al. 2009). An acoustic based density study focused on the latter time period would be less likely to portray daily changes in goliath grouper sound production and density. Therefore, prior to designing an efficient replicable long-term acoustic monitoring methodology, an understanding of reproductive and acoustic behavior over the course of the entire day and extended temporal scales is essential. Once species-specific behavioral patterns are known, processing efficiency can be increased by selecting a sampling schedule that accurately yields acoustic behavioral patterns at the desired scale.

The 2 measurements of sound production utilized differed in terms of processing efficiency. Calculating mean band level was quick and time efficient, while manually counting total vocalizations per file visually and audibly was more time consuming. However, it is arguable that information gathered from the manual examination of files exceeded what could have been inferred solely from band level measurements. Processing audio files manually reveals what other soniferous species are present at a given site and may lead to new discoveries of habitat use or behavioral patterns for targeted and untargeted species.

Both mean band levels $\mathrm{h}^{-1}$ and standardized vocalizations $\mathrm{h}^{-1}$ revealed similar temporal patterns and amplitudes from November to April. The significant relationship between the 2 measurements implies that they are interchangeable given the conditions at ALS. However, this may not be true for other locations; band levels incorporate all sources of sound within the selected frequency band, such as sound from boats, wind, other fishes, and marine mammals. If ALS had other aggregating soniferous species with either frequent or high-energy vocalizations within the 100 to $200 \mathrm{~Hz}$ band, such as yellowfin grouper Mycteroperca venenosa (Schärer et al. 2012) or red grouper Epinephelus morio (Nelson et al. 2011), band levels would have been influenced by the acoustic signals of these species. As a result, multispecies spawning aggregations may require the manual processing of acoustic data. However, in the case of red hind and yellowfin grouper in $\mathrm{PR}$, each species typically spawns during different months, with red hind spawning from December to February and yellowfin grouper in March to May. Therefore, if the biology and reproductive behaviors of individual species are known, band levels can still be used if the investigator can confidently identify and isolate the source species. Our study area did not have this complication during the spawning period; red hind were the only species consistently producing high intensity sounds within the 100 to $200 \mathrm{~Hz}$ band from November till May, and vessel associated sound was nearly absent. Beginning in March, the DSG unit did record the calls of humpback whales, which accounted for the isolated high mean band levels in the month of March.

The red hind densities estimated from UVC surveys and predicted from sound measurements portray temporal patterns that have been documented at other aggregation sites (Nemeth et al. 2007). Predicted densities built and rapidly fell for the December and January full moons, with a percentage of individuals remaining on site between moons. The surveyed and predicted densities depict large daily changes in fish abundance over the spawning season at a resolution unattainable with traditional methods. Sound production and predicted densities suggest that the January spawning event was larger than the December event, which is corroborated by previous studies and predictions given the timing of the December and January full moons in relation to the winter solstice (Nemeth et al. 2007, Cushion et al. 2008).

The timing of peak predicted density and peak sound production for January was 7 DAFM, which is later in the lunar cycle than peak densities and presumed spawning at other known red hind aggregation sites in PR and the USVI. Colin et al. (1987) reported spawning 1 DAFM, Shapiro et al. (1993a) and Nemeth et al. (2007) found densities to peak on the day of the full moon, while Whiteman et al. (2005) deduced that spawning likely occurred onward from 3 days prior to the full moon. In 2007, Mann et al. (2010) also documented a delay in peak red hind sound production at ALS when compared to another aggregation site at Mona Island, PR. The timing of spawning in relation to lunar periodicity appears to differ among sites but not within sites. Passive acoustic units can be deployed at a number of aggregations with limited effort to quantify differences in sound production, density, and spawning patterns among sites and years. Long-term acoustic studies have the ability to accurately predict the months and days that aggregations form and spawning likely occurs at a site specific level. Site idiosyncrasies may be a product of environmental conditions, such as temperature and ocean currents (Nemeth et al. 2007, 2008), and should be addressed in future studies.

By surveying over a fixed area, density for ALS was documented within a $0.04 \mathrm{~km}^{2}$ portion of the greater spawning aggregation area, and hence, these density estimations are not technically random with 
respect to the entire aggregation site, which was both wider and longer. Therefore, the area surveyed likely extended beyond the sound reception range of the DSG recorder. Additionally, the sound measurements were not calibrated for changes in oceanographic conditions, such as wind, seas, and ambient noise that may have altered the band level measurements and detection radius of the DSG on a daily basis. The $105 \mathrm{~dB}$ re $1 \mu \mathrm{Pa}$ band level threshold set for the inclusion of vocalizations in daily totals and regressions did not account for the contribution of ambient noise to band level measurements; thus, the measured individual vocalization band levels were a sum of fish and ambient noise energy. As a result, the recorded sound measurements should be considered as relative indices of density that did not directly correspond to densities over the entire aggregation or within the entire survey area but did portray relative daily changes in density. If sea conditions and red hind density, cluster distribution, and behavioral patterns were assumed to be uniform over the entire aggregation site and study period, then sound levels could be used to predict fish density for the entire site. To determine the exact density to which sound levels correspond, studies of red hind sound propagation and the role of oceanographic conditions on sound measurements at ALS must be conducted. With knowledge of propagation loss for red hind vocalizations in variable conditions, a radius of detection could be determined and be used to survey and calculate density within the range of the DSG recorder.

Only male red hind are believed to produce reproductive vocalizations (Mann et al. 2010); thus, it is possible that sound production only reflects male densities. Males have been found to arrive at the aggregations site prior to females (Whiteman et al. 2005, Nemeth et al. 2007) to establish territories (Colin et al. 1987); therefore, if male acoustic behavior was independent of female presence and was only a product of territoriality among males, sound production should appear to be roughly constant throughout the time males are located at the aggregation site. The recordings at ALS after the full moons contradict the idea that sound production is solely male density driven. Recorded vocalizations during male-male and male-female interactions suggest males vocalize as part of both courtship and territorial behaviors (Mann et al. 2010). Therefore, it is probable that the arrival of females induces increases in male acoustic territorial competition and courtship behaviors. As a result, sound production likely reflects the densities of both males and females. Stimuli for red hind acoustic behaviors need to be studied to understand the effects of male and female densities on sound production at spawning aggregations.

Sound production and densities over the entire sampling period highlight the abrupt changes in fish densities and behaviors that occur during the red hind spawning season at ALS. These rapid increases in density have historically been targeted by fishermen, often yielding large short-term profits with limited effort. Densities during the January spawning event increased nearly 35 -fold over the non-spawning season density. The prominent localization of red hind during such a short period of time leaves little doubt that fishing aggregations can have dramatic and quickly felt negative impacts on a spawning stock whose home range supports an entire fishery. Unfortunately, red hind are still being landed, bought, and sold in PR during the spawning season with little resistance from regulatory enforcement, despite the current seasonal protections (authors' pers. obs.), and this pressure is likely preventing the level of red hind stock recovery seen in the USVI (Nemeth 2005).

Evaluating the effects of closed areas and seasonal fishing bans is crucial for the support of current and future management strategies. Vocalization totals or received sound band levels from passive acoustic recordings may be used as a proxy for density to determine the effectiveness of management protections, resulting in data collection at a higher temporal resolution than may be possible with traditional methods. Yearly changes in densities can be monitored by analyzing changes in levels of sound production. Red hind sound production can also be used to study the timing of migrations to and from aggregation sites and presumed spawning, providing important information on site usage and when regulatory enforcement efforts should be maximized. With knowledge of the acoustic behavior of a targeted species, acoustic sampling schedules can be chosen to answer specific questions while increasing data processing efficiency. Additionally, signal processing and acoustic technologies are constantly improving and may be able to accurately carry out automated vocalization detections in the near future, enabling batch processing of data in near real-time. Red hind sound production and inferred densities can be monitored at a number of sites simultaneously to document daily, monthly, and yearly changes, help assess the condition and productivity of red hind stocks, and provide important information for fisheries managers and stakeholders. 
Acknowledgements. We thank all the volunteer divers who assisted with data collection, especially D. Mateos Molina and D. Sanabria, as well as the dedicated crew of the 'Tourmarine.' M. Craig and F. Pagán provided insightful advice and vital technical support. We are grateful to the Department of Marine Sciences of the University of Puerto Rico Mayagüez and the Caribbean Coral Reef Institute (CCRI) for administrative and research vessel assistance. This research and the resulting publication was made possible by funding from the National Oceanic and Atmospheric Administration (NOAA), Center for Sponsored Coastal Ocean Research (CSCOR), award NA10NOS4260223 to CCRI.

\section{LITERATURE CITED}

Aguilar-Perera A (2006) Disappearance of a Nassau grouper spawning aggregation off the southern Mexican Caribbean coast. Mar Ecol Prog Ser 327:289-296

Aguilar-Perera A, Aguilar-Dávila W (1996) A spawning aggregation of Nassau grouper, Epinephelus striatus (Pisces: Serranidae) in the Mexican Caribbean. Environ Biol Fishes 45:351-361

Beets J, Friedlander A (1992) Stock analysis and management strategies for red hind, Epinephelus guttatus, in the U.S. Virgin Islands. Proc Gulf Caribb Fish Inst 42:66-80

Beets J, Friedlander A (1999) Evaluation of a conservation strategy: a spawning aggregation closure for red hind, Epinephelus guttatus, in the U.S. Virgin Islands. Environ Biol Fishes 55:91-98

CFMC (1996) Regulatory amendment to the fishery management plan for the reef fish fishery of Puerto Rico and the United States Virgin Islands concerning red hind spawning aggregation closures including a regulatory impact review and environmental assessment. Caribbean Fishery Management Council, San Juan, Puerto Rico

Coleman FC, Koenig CC, Collins LA (1996) Reproductive styles of shallow-water grouper (Pisces: Serranidae) in the eastern Gulf of Mexico and the consequences of fishing spawning aggregations. Environ Biol Fishes 47: 129-141

Colin PL, Shapiro DY, Weiler D (1987) Aspects of the reproduction of two groupers, Epinephelus guttatus and E. striatus, in the West Indies. Bull Mar Sci 40:220-230

Cummings NJ, Parrack ML, Zweifel JW (1996) The status of red hind and coney in the U.S. Virgin Islands between 1974 and 1992. Proc Gulf Caribb Fish Inst 49:357-397

Cushion M, Cook M, Schull J, Sullivan-Sealey KM (2008) Reproductive classification and spawning seasonality of Epinephelus striatus (Nassau grouper), E. guttatus (red hind) and Mycteroperca venenosa (yellowfin grouper) from The Bahamas. Proc 11th Int Coral Reef Symp, Fort Lauderdale, FL, 2:1001-1005

Domeier ML, Colin PL (1997) Tropical reef fish spawning aggregations: defined and reviewed. Bull Mar Sci 60: 698-726

Federal Register (2005) Fisheries of Caribbean, Gulf of Mexico, and South Atlantic: comprehensive amendment to the Fishery Management Plans of the US Caribbean. 50 Code Federal Regulations Part 600 and 622, United States Government Printing Office, Washington, DC, p 62073-62084

García-Sais J, Appeldoorn R, Battista T, Bauer L and others (2008) The state of coral reef ecosystems of Puerto Rico.
In: Waddell JE, Clarke AM (eds) The state of coral reef ecosystems of the United States and Pacific Freely Associated States: 2008. NOAA Technical Memorandum NOS NCCOS 73. NOAA/NCCOS Center for Coastal Monitoring and Assessment's Biogeography Team, Silver Spring, MD, p 75-116

> Locascio JV, Mann DA (2008) Diel patterns of fish sound production in Charlotte Harbor, FL. Trans Am Fish Soc 137:606-615

Luckhurst BE, Trott TM (2008) Seasonally-closed spawning aggregation sites for red hind Epinephelus guttatus): Bermuda's experience over 30 years (1974-2003). Proc Gulf Caribb Fish Inst 61:331-336

> Luczkovich JJ, Sprague MW (2002) Using passive acoustics to monitor estuarine fish populations. Bioacoustics 12: 289-291

> Luczkovich JJ, Sprague MW, Johnson SE, Pullinger RC (1999) Delimiting spawning areas of weakfish Cynoscion regalis (family Sciaenidae) in Pamlico Sound, North Carolina using passive acoustic surveys. Bioacoustics 10: 143-160

> Luczkovich JJ, Mann DA, Rountree RA (2008a) Passive acoustics as a tool in fisheries science. Trans Am Fish Soc 137:533-541

Luczkovich JJ, Pullinger RC, Johnson SE, Sprague MW (2008b) Identifying sciaenid critical spawning habitats by the use of passive acoustics. Trans Am Fish Soc 137: 576-605

Mann DA, Locascio JV (2008) Acoustic communication in fishes. Bioacoustics 17:43-45

Mann DA, Hawkins AD, Jech JM (2008) Active and passive acoustics to locate and study fish. In: Webb JF, Popper AN, Fay RR (eds) Fish bioacoustics. Springer, New York, NY, p 279-309

> Mann DA, Locascio JV, Coleman FC, Koenig CC (2009) Goliath grouper Epinephelus itajara sound production and movement patterns on aggregation sites. Endang Species Res 7:229-236

Mann D, Locascio J, Schärer M, Nemeth M, Appeldoorn R (2010) Sound production by red hind Epinephelus guttatus in spatially segregated spawning aggregations. Aquat Biol 10:149-154

Marshak AR, Appeldoorn RS (2007) Evaluation of seasonal closures of red hind, Epinephelus guttatus, spawning aggregations to fishing of the west coast of Puerto Rico using fishery-dependent and independent time series data. Proc Gulf Caribb Fish Inst 60:566-572

> Myrberg AA Jr (1997) Underwater sound: its relevance to behavioral functions among fishes and marine mammals. Mar Freshwat Behav Physiol 29:3-21

Nelson MD, Koenig CC, Coleman FC, Mann DA (2011) Sound production of red grouper Epinephelus morio on the West Florida Shelf. Aquat Biol 12:97-108

Nemeth RS (2005) Population characteristics of a recovering US Virgin Islands red hind spawning aggregation following protection. Mar Ecol Prog Ser 286:81-97

Nemeth RS (2012) Species case studies: red hind-Epinephelus guttatus. In: Sadovy de Mitcheson Y, Colin PL (eds) Reef fish spawning aggregations: biology, research and management. Springer, New York, NY, p 412-417

> Nemeth RS, Blondeau J, Herzlieb S, Kadison E (2007) Spatial and temporal patterns of movement and migration at spawning aggregations of red hind, Epinephelus guttatus, in the U.S. Virgin Islands. Environ Biol Fishes 78: 365-381 
Nemeth RS, Kadison E, Blondeau JE, Idrisi N and others (2008) Regional coupling of red hind spawning aggregations to oceanographic processes in the eastern Caribbean. In: Grober-Dunsmore R, Keller BD (eds) Caribbean connectivity: implications for marine protected area management. Proc Spec Symp 9-11 November 2006, 59th Ann Meet Gulf Caribb Fish Inst, Belize City, Belize. Mar Conserv Ser ONMS-08-07. US Department of Commerce, National Oceanic and Atmospheric Administration, Office of National Marine Sanctuaries, Silver Spring, MD, p 170-183

PR DRNA (Puerto Rico Department of Natural and Environmental Resources) (2004) Reglamento de pesca de Puerto Rico. Departamento de Estado Reglamento Número 6768

PR DRNA (Puerto Rico Department of Natural and Environmental Resources) (2007) Enmedias al reglamento de pesca de Puerto Rico (Reglamento Número 6768), según enmendado (Reglamento Número 6902)

Rountree RA, Gilmore RG, Goudey CA, Hawkins AD, Luczkovich JL, Mann DA (2006) Listening to fish: applications of passive acoustics to fisheries science. Fisheries 31:433-446

Rowell TJ, Appeldoorn RS, Rivera JA, Mann DA, Kellison T, Nemeth M, Schärer-Umpierre MT (2011) Use of passive acoustics to map grouper spawning aggregations, with emphasis on red hind, Epinephelus guttatus, off western Puerto Rico. Proc Gulf Caribb Fish Inst 63:139-142

Sadovy Y (1994) Grouper stocks of the western central Atlantic: the need for management and management needs. Proc Gulf Caribb Fish Inst 43:43-64

Sadovy Y, Domeier M (2005) Are aggregation-fisheries sustainable? Reef fish fisheries as a case study. Coral Reefs 24:254-262

Editorial responsibility: Nicholas Tolimieri, Seattle, Washington, USA
Sadovy Y, Figuerola M (1992) The status of the red hind fishery in Puerto Rico and St. Thomas as determined by yield-per-recruit analysis. Proc Gulf Caribb Fish Inst 42: 23-38

Sadovy Y, Rosario A, Román A (1994) Reproduction in an aggregating grouper, the red hind, Epinephelus guttatus. Environ Biol Fishes 41:269-286

Schärer MT, Nemeth MI, Mann D, Locascio J, Appeldoorn RS, Rowell TJ (2012) Sound production and reproductive behavior of yellowfin grouper, Mycteroperca venenosa (Serranidae), at a spawning aggregation. Copeia 1: 136-145

Shapiro DY, Sadovy Y, McGehee MA (1993a) Size, composition, and spatial structure of the annual spawning aggregation of the red hind, Epinephelus guttatus (Pisces: Serranidae). Copeia 1993:399-406

Shapiro DY, Sadovy Y, McGehee MA (1993b) Periodicity of sex change and reproduction in the red hind, Epinephelus guttatus, a protogynous grouper. Bull Mar Sci 53: 1151-1162

Shapiro DY, Garcia-Moliner G, Sadovy Y (1994) Social system of an inshore stock of the red hind grouper, Epinephelus guttatus (Pisces: Serranidae). Environ Biol Fishes 41: 415-422

- Walters S, Lowerre-Barbieri S, Bickford J, Mann D (2009) Using a passive acoustic survey to identify spotted seatrout spawning sites and associated habitat in Tampa Bay, Florida. Trans Am Fish Soc 138: 88-98

> Whiteman EA, Jennings CA, Nemeth RS (2005) Sex structure and potential female fecundity in a Epinephelus guttatus spawning aggregation: applying ultrasonic imaging. J Fish Biol 66:983-995

Submitted: February 24, 2012; Accepted: May 23, 2012 Proofs received from author(s): August 7, 2012 